\title{
Pengembangan website koleksi langka Perpustakaan UGM sebagai preservasi digital heritage menuju era industri 4.0
}

\author{
Maryono $^{1}$, Mardi Pramono ${ }^{2}$ \\ 1,2 Perpustakaan Universitas Gadjah Mada \\ Jl. Bulaksumur, Kotak Pos 16, Depok, Sleman, Daerah Istimewa Yogyakarta, 55281 \\ E-mail: ${ }^{1}$ masyono@ugm.ac.id, ${ }^{2}$ mardi.fib@ugm.ac.id
}

Received: August 2019; Accepted: February 2020; Published: June 2020

\begin{abstract}
Preserving rare collections is very important, considering the historical value in them, through digitalization and website development as the digital heritage preservation. The Google analytics data showed that the performance of UGM Library's rare collection website was still not significant, in terms of the number of users, visits, duration of visits, and repeat visits are still far from expectations. The purpose of this research was to find out the performance and use of the website, to find out the site that the user wants, and to formulate the development formula. The study used a combination of methods, through survey data collection with closed and open questionnaires plus interviews to deepen the problem: quantitative and qualitative analyses were performed, plus documentary analysis. The results showed that the website's performance was not yet encouraging; users wanted changes to 5 elements, namely appearance, visual appeal, information content, timely information, and ease of interaction. Expected developments include new historical nuances; installation of flipping book viewers and infographics; link addition; indexes, annotations, and recommended search; addition of reviews and social media columns. Google analytic data shows the need to reduce loading times by compressing PDF files and improving design according to mobile devices. Qualitative analysis succeeded in capturing the desire to access digital versions of Indonesian manuscripts in the Netherlands and the United Kingdom, and the need for additional graphic designer staff to improve the appearance and visual appeal.
\end{abstract}

Keywords: Rare collection; Digital preservation; Website development; UGM Library; Webqual 4.0

\begin{abstract}
Abstrak
Koleksi langka sangat penting dilestarikan mengingat nilai sejarah di dalamnya, melalui digitalisasi dan pengembangan website sebagai preservasi digital heritage. Berdasarkan data google analytics, terlihat bahwa kinerja website koleksi langka Perpustakaan UGM masih sangat rendah, baik dari jumlah pengguna, kunjungan, durasi kunjungan maupun kunjungan berulang masih jauh dari harapan. Tujuan penelitian ini hendak mengetahui kinerja dan keterpakaian website, mengetahui website yang dikehendaki pengguna, dan menyusun rumusan pengembangannya. Penelitian ini menggunakan metode kombinasi, melalui pengumpulan data survei dengan kuesioner tertutup dan terbuka ditambah wawancara untuk memperdalam permasalahan. Analisis secara kuantitatif dan kualitatif, yang ditambah analisis dokumenter. Hasil penelitian menunjukkan bahwa kinerja website belum menggembirakan, pengguna menghendaki perubahan pada 5 unsur, yaitu tampilan, daya tarik visual, konten informasi, informasi tepat waktu, dan kemudahan interaksi. Adapun pengembangan yang diharapkan meliputi desain baru bernuansa sejarah, pemasangan flippingbook viewer, dan infografik, penambahan link, indeks, anotasi, dan recommended search, penambahan kolom ulasan dan sosial media. Sesuai data google analytic menunjukkan bahwa perlunya mengurangi waktu loading, menggunakan kompresi file $p d f$, dan perbaikan rancangan sesuai piranti mobile. Analisis kualitatif berhasil menjaring keinginan untuk mengakses versi digital dari manuskrip Indonesia di Belanda dan Inggris, serta kebutuhan dalam penambahan staf desainer grafis yang diharapkan mampu memperbaiki tampilan dan daya tarik visual.
\end{abstract}

Kata Kunci: Koleksi langka; Preservasi digital; Pengembangan website; Perpustakaan UGM; Webqual 4.0 


\section{PENDAHULUAN}

Website koleksi langka berisi konten digital sebagai hasil proses digitalisasi buku langka. Kajian di dalamnya banyak berisi sejarah, adat istiadat, kesenian, atau pun kesusasteraan. Berdasarkan fungsinya, website koleksi langka dapat dikategorikan sebagai website untuk mengarsipkan (archieve site), yang dirancang untuk mengumpulkan dan menyimpan konten digital berupa file atau laman website agar tidak hilang atau punah. Menurut Nielsen (2016), terdapat beberapa alasan dalam mengarsipkan konten: 1) untuk mempertahankan warisan budaya digital (digital heritage), 2) untuk memastikan keberlanjutan akses dan melestarikan konten sebagai obyek riset, 3) agar mampu menyimpan dan mendukung penyelesaian suatu kasus atau suatu riset yang membutuhkan catatan informasi masa lampau. Berdasarkan pantauan data google analytics pada kurun 1 Oktober 2018 - 31 Mei 2019, kinerja website koleksi langka Perpustakaan Universitas Gadjah Mada (UGM) yang beralamat pada website, http://langka.lib.ugm.ac.id/ masih sangat rendah dan cenderung stagnan. Sesuai data dalam website ini, data jumlah pengguna (users) sebanyak 4.119; jumlah kunjungan (sessions) sebanyak 5.056; jumlah kunjungan tiap pengguna (number of sessions per user) sebanyak 1.23; jumlah laman diakses setiap kunjungan (pages per session) sebanyak 6.54; rerata durasi setiap kunjungan (avg. session duration) sebesar 00.02.50; serta jumlah pengunjung berulang (returning visitors) sebanyak 453 (9,9\%).

Google analytic adalah aplikasi yang disediakan google untuk memantau lalu lintas kunjungan website. Informasi statistik yang dihasilkan, menjadi dasar penyusunan kebijakan, pengelolaan dan pengembangan website, dan telah secara luas diaplikasikan terutama dalam bidang pemasaran dan bisnis. Tujuan utama penerapan google analytic ialah untuk melakukan optimization website.

$$
\text { Hendriadi and Dedih (2014) }
$$

menjelaskan informasi statistik yang dihasilkan google analytic, di antaranya: visitor, new visitor, returning visitor, active users, sessions, avg session duration, pageviews, pages per session, dan bounce rate. Visitor ialah data yang menunjukkan jumlah pengunjung website. New visitor adalah data jumlah pengunjung yang pertama kali berkunjung ke website. Adapun returning visitor, data pengunjung yang berkunjung kembali ke website. Active users adalah jumlah pengguna aktif. Sessions ialah data yang menunjukkan kunjungan, dan kepopuleran website. Avg session duration, data yang menunjukkan durasi waktu setiap kunjungan. Pageviews yakni keseluruhan halaman konten yang diakses pengunjung. Pages per session, jumlah laman yang diakses setiap kunjungan. Bounce rate, sebagai persentase pengunjung yang hanya membuka 1 halaman dan langsung keluar

Penerapan web analytic memiliki siklus yang sederhana. Menurut Bekavac and Pranicevic (2015), web analytic terdiri dari empat tahapan. Tahap pertama, measuring, menggabungkan berbagai ukuran berbeda dan dinyatakan dalam angka, rasio, dan Indikator Kinerja Kunci (IKK). Kedua, data acquisition, pengumpulan data terutama dilakukan melalui dua metode yang paling luas digunakan, yaitu menggunakan log files dari server, dan menggunakan metode khusus untuk menandai situs website. Ketiga, analyzing data, yaitu mengolah data menjadi informasi yang berguna bagi pengambilan keputusan. Keempat, reporting of data, menyusun laporan 
berdasarkan ukuran metrik yang dipilih, dan berguna bagi manajemen perusahaan.

Baltes (2015) menjelaskan strategi pemasaran konten, bahwa strategi biasanya disesuaikan dengan kondisi tiap organisasi. Strategi tersebut umumnya terdiri dari unsur tujuan pemasaran konten, analisis target, jenis pemasaran, saluran promosi, penjadwalan dan pengukuran kinerja. Tujuan pemasaran mencakup tindakan dalam meningkatkan kesadaran merek, membangun hubungan dengan pelanggan, menarik pelanggan ke produk, memecahkan masalah dalam kurangnya pengunjung, menciptakan kebutuhan terhadap produk yang spesifik, mengembangkan kesetiaan pelanggan, pengujian produk, dan meningkatkan penjualan.

Koleksi langka dipahami sebagai buku yang jumlahnya sedikit dan sukar ditemukan. Hal ini berkaitan dengan tahun terbit, isi buku, nilai produksi maupun nilai ekonomi. Ciri-ciri koleksi langka disebutkan Margana (2013) di antaranya dokumen telah berusia tua, jumlah sangat terbatas dan tidak ada di pasaran, tidak ditulis atau diterbitkan kembali, dan memiliki keunikan bahasa maupun isi. Koleksi langka banyak berisi informasi warisan budaya (cultural heritage). Shimray and Ramaiah (2017) mendefinisikan warisan budaya sebagai ekspresi, adat istiadat, ritual, artefak, nilai-nilai yang dikembangkan beberapa generasi, yang berwujud (tangible) maupun tidak berwujud (intangible), yang diwarisi dari generasi sebelumnya, dan menghubungkan masa lampau dan masa kini, sehingga merupakan kunci bagi masyarakat dalam menemukan jati dirinya. Hasil dari proses digitalisasi tersebut, menurut $\mathrm{He}, \mathrm{Ma}$, and Zhang, (2017) didefinisikan sebagai warisan budaya digital (digital heritage) yaitu gabungan warisan budaya dengan teknologi digitalisasi, pengetahuan digital dengan risetnya, mencakup bukan hanya aspek konvensional (koleksi digital dan dokumentasi, riset digital dan manajemen informasi, presentasi digital dan intrepretasi), tetapi juga kreasi dan penggunaan konten digital (hak cipta warisan budaya, wisata budaya, film dan media). Naskah kuno dan koleksi langka telah menjadi pilihan strategi branding Perpustakaan Nasional. Ali (2012) menyebutkan bahwa semenjak strategi branding dijalankan, tiga manuskrip Indonesia telah mendapatkan pengakuan Unesco sebagai memory of the world, yaitu Nagara Kertagama, La Galigo serta Babad Dipanegara.

Digitalisasi dan website merupakan bentuk preservasi digital. Tripathi (2018) menjelaskan preservasi digital sebagai keseluruhan tahap untuk memastikan aksesibilitas konten digital. Tindakan preservasi mencakup preventif maupun kuratif. Preservasi preventif yaitu pengaturan, pencegahan dan perlindungan dari musibah yang tidak diharapkan. Preservasi kuratif dimaksudkan untuk memperbaiki obyek yang telah rusak atau terancam bahaya kerusakan. Pustakawan menghadapi berbagai resiko dalam upaya preservasi digital. Tripathi (2018) lebih lanjut menjelaskan berbagai resiko yang dihadapi preservasi digital, di antaranya permasalahan krisis dan perubahan fungsi organisasi, perubahan kebijakan dan pendanaan organisasi, pergantian pimpinan dan staf ahli, kerusakan sistem temu kembali informasi, permasalahan hak cipta, pelaksanaan outsourcing tanpa perencanaan masa mendatang, format file sudah usang sehingga tidak lagi yang dapat diakses, dan media penyimpanan sudah usang sehingga data tidak dapat 
diselamatkan. Selain itu, kerusakan media penyimpanan yang dapat menghancurkan data, kehilangan informasi penting dalam media penyimpanan, kehilangan informasi sumber asli yang menghasilkan keraguan orisinalitas informasi, human error yang mengakibatkan terhapusnya data, data arsip digital yang jarang diakses akan lebih tinggi resiko kerusakannya, serta bencana alam yang merusak infrastruktur bangunan.

Boro (2018) menjelaskan adanya tuntutan kebutuhan yang berkembang terhadap upaya preservasi digital di masa mendatang. Pertama, layanan preservasi lintas unit/organisasi, mewujudkan jaringan arsip global. Kedua, layanan interaktif dan visual, eksplorasi arsip dengan melihat, mendengar, mengamati, dan mengerjakan (learning by seeing, reading, hearing, observing, and doing). Ketiga, dukungan Teknologi Informasi (TI) dan Sumber Daya Manusia (SDM) preservasi digital.

Inovasi sains dan teknologi yang semakin cepat, telah menghadirkan era baru industri 4.0 yang diprediksi akan mengintegrasikan internet dengan aneka peralatan (internet of things), aneka jasa (service), serta aneka sarana industri (smart factory). Proses integrasi berbagai unsur tersebut membutuhkan peran teknologi jaringan dan fitur kecerdasan buatan (artificial intelligence) yang sangat dominan. Inovasi teknologi ini akan sangat banyak menghadirkan layanan maya (virtual) dan tanpa awak (self-service). Pada era 4.0, internet menghubungkan informasi, orang, pengetahuan, dan juga berbagai kecerdasan buatan. Subagyo (2018) menjelaskan, isu besar pada era 4.0 bukanlah pada "bagaimana menyimpan", tetapi bagaimana klasifikasinya, penelusurannya, serta pengamanannya secara efisien. Manajemen data (research data management) menjadi tugas strategis yang akan dilakukan pustakawan agar tetap survive menghadapi era tersebut. Perpustakaan harus melakukan transformasi sesuai perkembangan sains dan teknologi menghadapi era industri 4.0. Berdasarkan kecenderungan tersebut, maka pengembangan website akan mengintegrasikan berbagai jaringan kerja sama. Pengembangan website juga bergerak ke arah interaktif, mengintegrasikan berbagai format digital dan audio visual, serta membutuhkan berbagai keahlian TI dan preservasi digital. Khanzode and Sarode (2016) menambahkan bahwa website di masa depan, cenderung menerapkan kecerdasan buatan (artificial intelligence) dan menciptakan interaksi cerdas dengan masyarakat penggunanya. Amarin (2015), menyebutkan bahwa terdapat kecenderungan semakin berperannya teknologi virtualisasi grafik tiga dimensi. Kehadiran video game ke dalam hiburan dan pendidikan juga telah nyata diterapkan. Menurut Richardson, Milovidov and Schmalzried (2017) pada tahun 2015, terdapat 1 dari 3 anak pernah memainkan game online. Ternyata, game dapat diterapkan ke dalam hampir semua kurikulum.

Richardson et al.

menyebutkan bahwa akses internet melalui perangkat mobile smartphone meningkat sangat dramatis. Menurut data Clement (2019), pada tahun 2018 akses internet melalui perangkat mobile telah mencapai $48,2 \%$ dari seluruh traffic internet. Berdasarkan kecenderungan tersebut, maka pengembangan website di masa mendatang harus mempertimbangkan aksesibilitas melalui perangkat mobile. Lebih lanjut Richardson, et al. (2017) menjelaskan, fleksibilitas akses internet di 
era industri 4.0, memberikan kesempatan lebih luas bagi siswa untuk mengeksplorasi topik yang menjadi fokus perhatian dan cara belajar yang berbeda secara tradisional. Di era tersebut, siswa akan sangat mudah melakukan eksperimen dalam menghasilkan produk digital online, bersimulasi ke berbagai hal, dan berkolaborasi secara global. Integrasi teknologi website dan perangkat pendidikan yang memacu inovasi dan kreativitas kewirausahaan, serta mendorong partisipasi aktif para siswa.

Berbagai metode dapat digunakan untuk mengkaji kualitas website, yang masing-masing terdiri dari variabel dan indikatornya. Pada umumnya kualitas dikaji dari sisi pengguna berdasarkan persepsi dan kepuasan. Metode tersebut di antaranya Seroqual, Webqual, Sitequal, WebqualTM, PeSQ, serta ASP. Nurhadi, Yunita, Mukhayaroh, and Sahirudin (2019) menjelaskan metode Webqual 4.0 lazim digunakan terdiri dari tiga variabel yaitu usability, information quality dan service interaction quality. Webqual adalah metode pengukuran kualitas website berdasarkan pada persepsi pengguna akhir. Dalam penelitian ini digunakan metode Webqual 4.0 ditambah satu variabel entertainment (Rezende, Moura, Vasconcelos, \& Cunha, 2017)

Kadar, Napitupulu, and Jati (2017) menjelaskan bahwa variabel Webqual 4.0 terdiri dari, "Usability, information quality, dan service interaction quality." Variabel usability terdiri dari atribut sebagai berikut, "Easy to operate, interaction with the website is clear and understandable, easy to navigate, easy to use, attractive appearance, design according to the type of website, conveys a sense of competency dan creates a positive experience for me."

Variabel information quality terdiri dari atribut, "Provides accurate information, provides believable information, provides timely information, provides relevant information, provides easy to understand information, provides information at the right level of detail, dan presents information in appropriate format." Variabel service interaction quality terdiri dari atribut, "Has good reputation, feels safe to complete transactions, my personal information feels secure, creates a sense of personalization, convey a sense of community, easy to communicate with the organization, dan feel confident that goods/services will be delivered as promised." Rezende, Moura, Vasconcelos, and Cunha (2017) menyebutkan variabel entertainment terdiri dari atribut, "Visual appeal-design aesthetic, emotional appeal-users are encouraged to continue to interact so as to create new experiences, dan innovativeness - creativity and authenticity of website design." Menurut Astuti and Sari (2016), kepuasan pelanggan (user satisfaction) adalah perasaan senang atau kecewa, kondisi ketika konsumen merasa puas terhadap produk atau jasa tertentu. Tingkatan suatu produk yang mampu memenuhi kebutuhan secara menyenangkan, dan kualitas produk yang mampu melampaui harapan. Kinerja berada di bawah harapan, pelanggan akan merasa tidak puas. Sebaliknya jika kinerja memenuhi harapan, pelanggan akan merasa puas.

Riset oleh Subrahmanyam (2017); Pramono, Sarma, and Munandar (2017); dan Napitupulu (2017) menunjukkan adanya keterkaitan antara kualitas dan kepuasan, bahwa kualitas berpengaruh langsung secara positif dan signifikan terhadap kepuasan. Pengguna yang merasa puas, diharapkan akan kembali dan lebih sering mengunjungi website. Dimensi kualitas webqual 4.0 berpengaruh terhadap kepuasan pengguna. Pengguna akan 
mengulangi kembali kunjungan ke dalam website.

Berbagai riset tentang kinerja website dengan google analytic dan analisis kepuasan pengguna website pernah dilakukan. Riset tersebut tidak satu pun tentang pengembangan website koleksi langka, juga tidak ada yang menggunakan gabungan atau kombinasi berbagai metode, pengumpulan dan analisis data seperti dalam penelitian ini.

Redkina (2018) melakukan studi potensi penggunaan google analytic dalam berbagai aspek pekerjaan perpustakaan di lingkungan website, di antaranya studi perilaku dan preferensi pengguna, analisis relevansi koleksi yang disediakan melalui website, analisis kebutuhan koleksi dan layanan, serta optimization kinerja website. Google analytic membantu meningkatkan produktivitas dan efektivitas pekerjaan perpustakaan. Studi oleh Redkina (2018) ini tidak bermaksud menghasilkan rumusan pengembangan website, baru sebatas studi kelayakan penggunaan google analytic untuk membantu tugas-tugas di perpustakaan. Studi oleh Andayani (2013) juga berusaha sebatas mengeksplorasi potensi pemanfaatan google analytics, tetapi dimaksudkan khusus untuk menganalisis kinerja Online Public Access Catalog (OPAC) atau Webpac.

$$
\text { Masrek and Gaskin }
$$
mengukur kepuasan pengguna terhadap website perpustakaan digital Universitas Teknologi MARA. Penelitian dilakukan untuk mengetahui faktor-faktor penentu kepuasan pengguna. Hasil penelitian menunjukkan kepuasan pengguna terutama ditentukan oleh faktor, "Information quality, systems quality, service quality, perceived usefulness, perceived ease of use dan cognitive absorption." Penelitian oleh Masrek and Gaskin (2016) ini berusaha menentukan faktor yang berpengaruh terhadap kepuasan pengguna, tidak berusaha menentukan unsur-unsur yang harus diperbaiki dan merumuskan pengembangan website.

Penelitian oleh Baiti, Suprapto, and Rachmadi (2017) mengevaluasi website Dinas Pendidikan Kota Malang, menggunakan metode kuantitatif dengan survei, serta tiga variabel webqual. Variabel webqual yang digunakan yaitu usability, information quality, dan service interaction quality. Analisis menggunakan metode kuadran IPA serta analisis kesesuaian. Hasil penelitian tersebut dinyatakan bahwa website Kota Malang tidak sesuai dengan harapan pengguna. Tiga atribut dinyatakan sebagai prioritas perbaikan yaitu informasi terkini, format informasi, dan kemudahan berkomunikasi. Penelitian tersebut berusaha menghasilkan rumusan perbaikan website, tetapi tidak didasarkan pada analisis data kinerja dari google analytics, serta tidak dilengkapi dengan data kualitatif dari pengguna dan pengembang website.

Rahayu, Utami, and Luthfi (2018) mengevaluasi kualitas website radio $\mathrm{MQ}$ 92,3 FM di Yogyakarta, dengan tujuan untuk pengembangan website. Penelitian tersebut menggunakan metode Webqual, dengan menyesuaikan variabel terhadap jenis website yang dianalisis. Pengumpulan data dengan kuesioner dan sampel ditentukan dari jumlah pendengar aktif serta masyarakat sekitar. Variabel yang digunakan terdiri dari usability, information quality, entertainment, dan complementary relationship. Metode Focus Group Discussion (FGD) juga digunakan bersama pengembang website untuk menentukan kelanjutan perbaikan website. Hasil penelitian tersebut, pada kuadran I ditemukan dua unsur yang menjadi 
prioritas perbaikan yaitu tersedianya halaman untuk mengunduh (download) konten, dan daftar (list) program siaran radio. Realisasi perbaikan berdasarkan harapan pengguna tersebut terkendala oleh sistem website yang digunakan, sehingga penambahan fitur baru tidak dimungkinkan. Penelitian oleh Rahayu, Utami, and Luthfi (2018) ini berusaha mencari rumusan pengembangan website, tetapi tidak menggunakan analisis data kinerja dari google analytics, juga tidak menggunakan analisis kesenjangan (gap analysis), selain itu data kualitatif juga sebatas FGD bersama pengembang website, bukan dari pengguna.

Website koleksi langka pada http://langka.lib.ugm.ac.id/ sebagai bentuk preservasi digital koleksi langka Perpustakaan UGM, mulai diluncurkan pada tahun 2014. Kondisi setelah berjalan lima tahun, pada tahun 2019 ini jumlah konten digital tercatat telah mencapai 1.500 judul, tetapi kinerjanya masih jauh dari harapan. Oleh karena itu, kajian dan rencana pengembangan dalam menghadapi era industri 4.0. penting segera dilakukan. Website perlu dirancang agar mudah digunakan, menarik secara visual, interaktif dan menyenangkan. Berdasarkan uraian latar belakang masalah, maka tujuan penelitian ini yaitu untuk, 1) mengetahui kinerja dan keterpakaian website koleksi langka melalui google analytic, 2) mengetahui website koleksi langka digital yang dikehendaki pengguna, 3) membuat rumusan usulan pengembangan website koleksi langka digital.

Penelitian ini berbeda dan belum pernah dilakukan, karena berusaha merumuskan pengembangan website koleksi langka digital menggunakan metode kombinasi dan berbagai analisis data. Analisis data dokumenter google analytic digunakan untuk mengetahui kinerja website. Analisis kesenjangan untuk mengetahui kepuasan berdasarkan kesenjangan antara kinerja dan harapan pengguna. Analisis kuadran IPA untuk menentukan unsur prioritas yang harus segera diperbaiki, serta dilengkapi analisis data kualitatif dari pengguna untuk menjaring masukan berharga dan triangulasi sumber dengan pengembang website.

Penelitian ini bermanfaat untuk menghasilkan rumusan pengembangan website koleksi langka digital menuju era industri 4.0. Selain itu, penelitian ini pun akan menghasilkan suatu skema evaluasi kinerja website, baik dengan analisis google analytic maupun dengan survei kualitas dan kepuasan pengguna. Adapun manfaat di bidang keilmuan, akan menambah kajian bidang kepustakawanan, yang menyerap banyak kemajuan sains teknologi informasi dan komunikasi. Kajian website koleksi langka ini juga akan meningkatkan pengembangan profesi pustakawan yang berusaha menyesuaikan kemajuan sains teknologi menuju era industri 4.0.

\section{METODE PENELITIAN}

Metode penelitian yang digunakan ialah metode kombinasi (mixed methods), metode kuantitatif dan kualitatif. Adapun model yang digunakan yaitu model concurrent embedded, merupakan penggabungan kedua metode yang dilakukan dengan tidak berimbang. Di mana komposisi dalam satu penelitian dimungkinkan 70\% kuantitatif dan 30\% kualitatif (kuantitatif sebagai penelitian primer), atau sebaliknya. Pengumpulan data dilakukan secara simultan, dalam satu tahap pengumpulan data. Setelah 
instrumen terbukti valid dan reliabel, selanjutnya digunakan untuk pengumpulan data kuantitatif bersamaan dengan data kualitatif. Pengumpulan data kuantitatif dilakukan menggunakan kuesioner tertutup, sedangkan pengumpulan data kualitatif menggunakan kuesioner terbuka, observasi, dan wawancara. Data kuantitatif dianalisis menggunakan statistik, sedangkan data kualitatif dianalisis secara kualitatif. Setelah digabungkan, maka dapat ditemukan data kualitatif yang memperluas dan memperkuat data kuantitatif. Data kuantitatif selanjutnya disajikan dalam bentuk tabel atau grafik, dilengkapi dengan data kualitatif, dan dilakukan pembahasan sehingga hasil penelitian semakin jelas.

Populasi dalam penelitian ini yaitu seluruh pemustaka di bagian koleksi langka Perpustakaan UGM dan Perpustakaan FIB UGM dalam sebulan. Metode penentuan sampel yang digunakan yaitu purposive sampling. Menurut Sugiyono (2011), metode tersebut dilakukan berdasarkan pertimbangan atau kriteria tertentu. Kriteria sampel dalam penelitian ini yaitu pemustaka yang pernah mengakses website langka.lib.ugm.ac.id, sejumlah 217 orang, yang didapatkan dari jumlah pengguna website dari google analytic sejumlah 2.359 orang (1 Oktober 2018 - 28 Februari 2019), atau 472 orang per bulan. Rono (2018) menjelaskan penentuan sampel dengan rumus Slovin sebagai berikut:

$$
\begin{aligned}
n & =\frac{N}{1+N(e)^{2}}=\frac{472}{1+472(0,05)^{2}} \\
& =\frac{472}{1+1,18}=\frac{59}{2,18}=216,51 \\
n & =\text { ukuran sampel } \\
N & =\text { ukuran populasi }
\end{aligned}
$$

$e=$ standar eror $(5 \%)$

$\mathrm{N}=$ jumlah seluruh pengguna yang mengakses 2.359 dalam 5 bulan $=2.359 / 5=$ 472 per bulan. Besar sampel $\mathrm{n}$ dibulatkan menjadi 217 responden. Variabel dalam penelitian ini adalah persepsi pengguna terhadap kualitas website koleksi langka digital menggunakan dimensi kualitas website metode Webqual 4.0 yang dimodifikasi. Ini lebih cocok digunakan karena fokus mengukur kualitas website, bukan aspek layanan. Hal ini juga karena adanya tuntutan pengembangan website yang semakin interaktif di masa depan, di mana salah satu dimensi Webqual adalah interaction quality.

Berdasarkan empat variabel disusun sebanyak 25 butir pernyataan. Variabel usability 8 butir, information quality 7 butir, service interaction quality 7 butir, dan entertainment 3 butir. Selain 25 butir pernyataan tersebut, survei juga bermaksud menjaring informasi perbaikan atribut website sesuai harapan pengguna dengan menggunakan pertanyaan terbuka. Variabel usability (U) terdiri dari sub variabel U1 website mudah dijalankan, U2 interaksi dengan website sangat mudah dipahami, U3 petunjuk di dalamnya sangat jelas dan mudah, U4 website mudah digunakan/diakses, U5 tampilan website sangat menarik, U6 desain sesuai jenis website, arsip koleksi langka digital, U7 website mampu meningkatkan kompetensi / kompetisi, dan U8 website memberi pengalaman positif. Variabel information quality terdiri dari I1 website menyediakan informasi akurat, I2 website menyediakan informasi terpercaya, I3 website menyediakan informasi tepat waktu, I4 website menyediakan informasi relevan, I5 website menyediakan informasi yang mudah dipahami, I6 website 
menyediakan informasi rinci, dan I7 website menyediakan informasi dalam format yang sesuai. Variabel service interaction quality terdiri dari S1 website mempunyai reputasi baik, S2 website memberi rasa aman berinteraksi, S3 informasi pribadi di website terjaga dan aman, S4 website menciptakan kesan pribadi, S5 website memiliki semangat komunitas, S6 website memudahkan berkomunikasi dengan organisasi, dan S7 merasa yakin urusan dengan website akan ditepati. Variabel entertainment terdiri dari E1 website memiliki daya tarik visual dan desain yang estetis, E2 website sangat menyenangkan pengguna dan menjadi pengalaman baru , dan E3 Desain website inovatif, kreatif dan otentik.

Angket penelitian ini menggunakan skala Likert. Likert's Summated Rating (LSR) menurut Sugiyono (2011) banyak digunakan untuk mengukur variabel penelitian sosial, seperti sikap, pendapat, dan persepsi sosial seseorang atau sekelompok orang. Skala Likert yang digunakan dengan rentang dari Sangat Tidak Setuju (STS) dengan nilai 1, Tidak Setuju (TS) nilai 2, Cukup Setuju (CS) nilai 3, Setuju (S) nilai 4, hingga Sangat Setuju (SS) nilai 5. Pengumpulan data dilakukan dengan metode dokumenter dari google analytic, survei kuesioner terbuka dan tertutup, serta wawancara. Data dokumenter google analytic diambil pada kurun 1 Oktober 2018 - 31 Mei 2019, sedangkan survei online dilaksanakan pada 1-31 Mei 2019. Wawancara dengan staf pengembang website dilakukan pada 31 Mei 2019 untuk pengujian keabsahan data sebagai triangulasi sumber.
Analisis data kuantitatif menggunakan analisis kesenjangan (gap analysis). Menurut Shia, Chen, Ramdansyah, and Wang (2016), kesenjangan terjadi apabila pengguna mempersepsikan kualitas pelayanan (quality of service) yang diterimanya lebih tinggi daripada desired service atau lebih rendah daripada adequate service kepentingan pelanggan tersebut. Dengan demikian, pelanggan dapat merasakan sangat puas atau sebaliknya sangat kecewa. Shia et al. (2016) lebih lanjut menjelaskan analisis kesenjangan diterapkan untuk mengetahui kesenjangan antara persepsi kualitas (actual) dan kualitas yang diharapkan (ideal).

$\begin{array}{ll}\mathrm{Q}(\mathrm{Gap}) & =\text { Perf }- \text { Imp } \\ \text { Gap } & =\text { Tingkat kesenjangan (level of } \\ & \text { the quality gap }) \\ \text { Perf } & =\text { Persepsi kualitas actual } \\ \text { Imp } & =\text { Kualitas ideal / harapan / } \\ & \text { kepentingan / kepuasan }\end{array}$

Nilai positif $Q \geq 0$, kualitas aktual sesuai dengan kualitas ideal yang diharapkan. Sebaliknya jika $Q<0$, maka tingkat kualitas belum mampu memenuhi harapan pengguna. Analisis kuantitatif juga menggunakan analisis kuadran IPA. Menurut Shia et al. (2016), ImportancePerformance Analysis (IPA) adalah teknik untuk mengidentifikasi atribut-atribut jasa (service) yang perlu diperbaiki (improvement), ataupun yang perlu dikurangi prioritasnya. Metode ini dikenal dengan analisis kuadran, lazim diterapkan karena menghasilkan proposal peningkatan kinerja atau kualitas. Ferreira and Fernandes (2015) menjelaskan penggabungan pengukuran persepsi dan tingkat kepuasan/kepentingan (importance) dalam diagram dua dimensi berikut. 


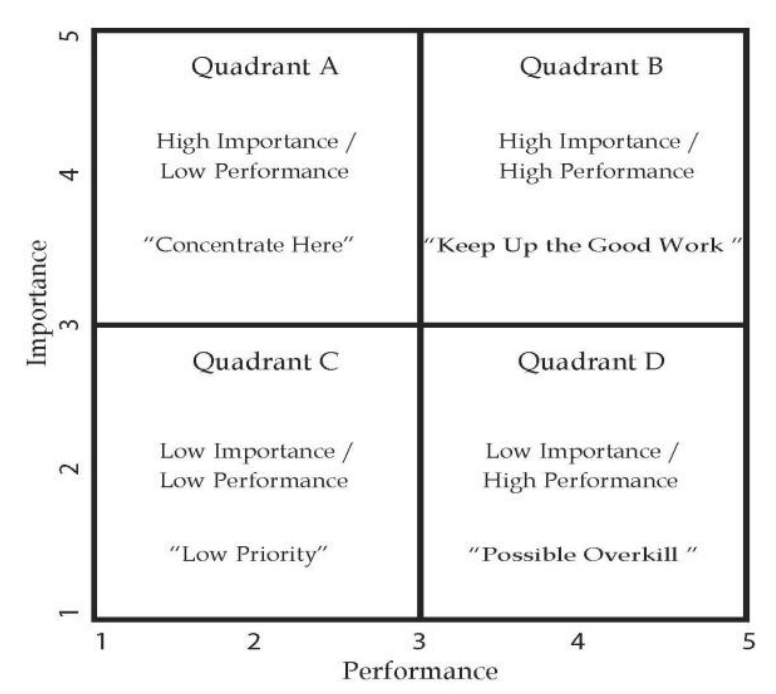

Gambar 1. Diagram importance/performance analysis Sumber: Ferreira and Fernandes, (2015)

Sesuai gambar ini, sumbu $\mathrm{x}$ menggambarkan persepsi kualitas website, sedangkan sumbu y menggambarkan harapan/kepentingan/kepuasan para pengguna. Kuadran I prioritas perbaikan. Kuadran II sebaiknya dipertahankan. Keunggulan produk/jasa ditentukan oleh variabel di kuadran ini. Kuadran III kurang prioritas, bisa diabaikan. Kuadran IV variabel yang berlebihan, bisa dikurangi untuk efisiensi.

Penelitian ini juga menggunakan metode kualitatif. Menurut Walidin, Saifullah, and Tabrani (2015), tujuan penelitian kualitatif adalah mencari pengertian yang mendalam tentang suatu gejala, fakta atau realita yang hanya dapat dipahami jika ditelusuri secara mendalam, tidak terbatas hanya di permukaan saja. Kedalaman ini yang menjadi ciri khas metode kualitatif, sekaligus faktor unggulan. Pengertian mendalam dapat diperoleh melalui observasi, wawancara dan pengalaman langsung. Data kualitatif dapat berbentuk kata-kata, kalimat catatan, gambar dan video, tetapi tidak berbentuk angka. Data kualitatif dikumpulkan melalui berbagai teknik pengumpulan data di antaranya wawancara, analisis dokumen, diskusi terfokus, atau observasi yang telah disusun dalam catatan (transkrip), juga gambar yang dikumpulkan melalui pemotretan dan rekaman video.

Analisis data kualitatif menghasilkan pemahaman, makna, pengertian, konsep, hipotesis atau teori baru. Langkah analisis data kualitatif yaitu proses mencari, menyusun, menata secara sistematis data dari hasil wawancara, kuesioner terbuka, catatan lapangan, dan bahan lainnya sehingga dapat mudah dipahami.

Analisis dilakukan dengan mengorganisasikan data, menjabarkan data, melakukan sintesis, menyusunnya ke dalam pola, memilah yang penting sehingga dapat ditarik kesimpulan. Aktivitas analisis mencakup reduksi data (data reduction), penyajian data (data display), serta penarikan kesimpulan dan verifikasi (conclusion drawing/ verification). Langkah selanjutnya pengujian keabsahan data menggunakan triangulasi, baik sumber, metode, maupun waktu. Alur kerja penelitian terlihat jelas dalam gambar 2.

Reduksi data dilakukan dengan langkah berikut, memilih, memilah, menyederhanakan, merangkum, memilih hal pokok, menemukan pola, serta membuang yang tidak diperlukan, dari berbagai catatan lapangan. Langkah tersebut dilakukan untuk meringkas dari banyaknya data lapangan.

Triangulasi sumber untuk menguji keabsahan data dilakukan dengan cara mengecek data yang telah diperoleh kepada beberapa sumber. Data kemudian dianalisis sampai menghasilkan kesimpulan. Selanjutnya penulis meminta kesepakatan sumber triangulasi. Di mana dalam penelitian ini, triangulasi sumber 
digunakan sumber informan pihak staf pengembang website.

Pemikiran strategis pentingnya website koleksi langka digital sebagai preservasi digital heritage di era industri 4.0

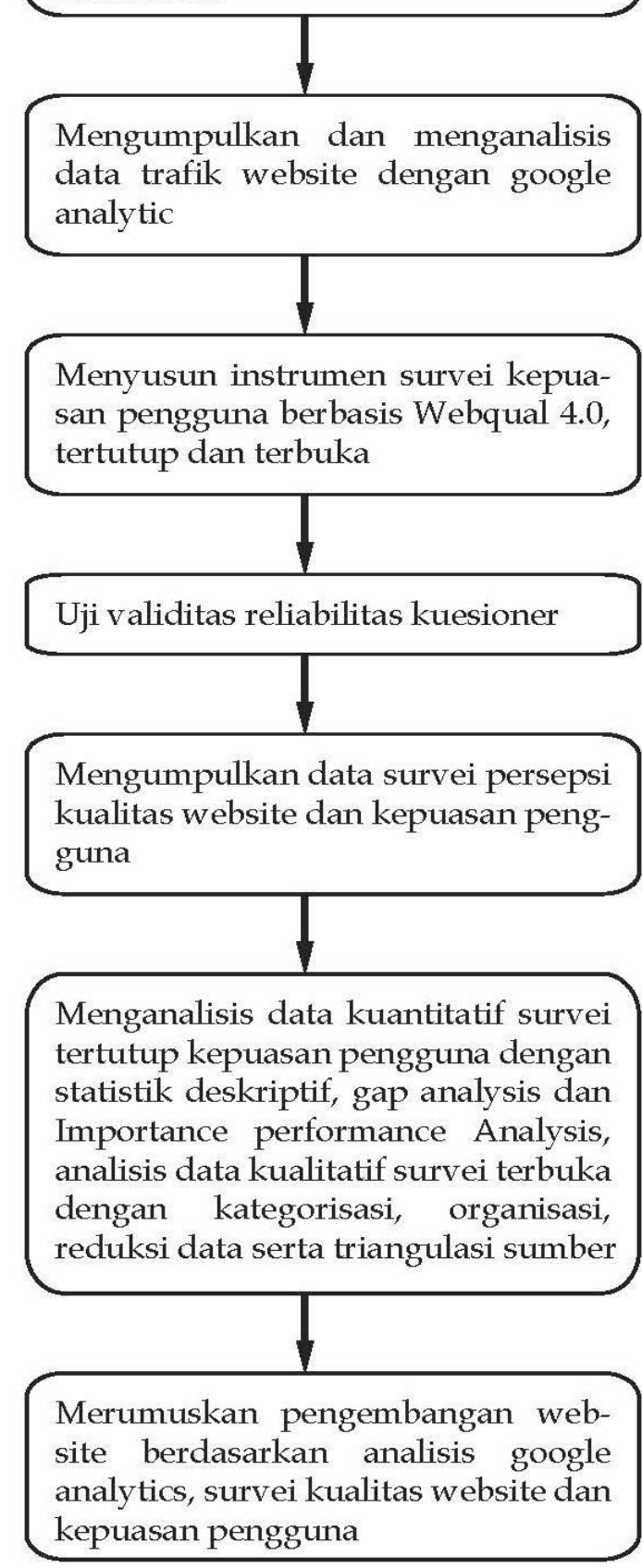

Gambar 2. Bagan alur kerja penelitian Sumber: Hasil penelitian, 2019

\section{HASIL DAN PEMBAHASAN}

Sesuai data dokumenter google analytics yang diambil pada kurun 1 Oktober 2018 - 31 Mei 2019, menunjukkan fakta kinerja website koleksi langka yang ditunjukkan pada tabel 1. Tabel tersebut memperlihatkan jumlah kunjungan yang belum menggembirakan, dalam waktu 8 bulan tercatat hanya 5.056 kunjungan, atau 21 kunjungan per hari. Data juga menunjukkan bahwa hanya 38,26\% menggunakan perangkat mobile, masih di bawah data statistik dunia sebesar 48,2\% (Clement, 2019). Implikasi pada pengembangan website harus disesuaikan menggunakan format akses mobile. Jumlah laman tiap kunjungan sebesar 6,54 bisa dimaklumi karena diterapkan pembatasan akses off site sejumlah 10 halaman. Jumlah pengunjung berulang sebanyak 9,9\%, diartikan bahwa website belum banyak berkesan, hanya sedikit yang mengulangi kunjungan. Durasi waktu berkunjung selama 2 menit 50 detik, menandakan bahwa pengunjung hanya sekedar melihatlihat sekilas dan kemudian pergi. Data tabel 1 juga menunjukkan waktu loading konten sebesar 13,21 detik, menjadi tantangan perbaikan, mengingat buku langka merupakan file image hasil proses scanning dan fotografi yang berukuran besar.

Pengumpulan data menggunakan kuesioner berhasil menjaring 217 responden, sebagian besar berpendidikan S1 sejumlah 153 orang (70,51\%), S2 sejumlah 42 orang (19,35\%), S0 sejumlah 13 $(5,99 \%)$ orang, dan S3 sejumlah 8 orang $(3,69 \%)$. Status responden sebagai mahasiswa sejumlah 191 orang (88,02\%), pemustaka umum sejumlah 18 orang $(8,29 \%)$, dosen dan peneliti masing-masing sejumlah 4 orang $(1,84 \%)$. Hasil olah data dengan tingkat signifikansi $\alpha=5 \%$; tabel untuk alfa $5 \%$ dan df $=66-2=64$ adalah 0.2423; nilai $r>0$ dan $>0.2423$, maka dapat dikatakan valid. Hasil perhitungan dengan SPSS, 25 butir dinyatakan valid semuanya. Hasil olah data dengan tingkat signifikansi $a=5 \%$; diperoleh Cronbach's alpha = 
0,980 $>0,60=\alpha$; reliabel. Hasil perhitungan dengan SPSS, ditentukan bahwa kuesioner persepsi kualitas aktual (25 item) dinyatakan valid dan reliabel semuanya.

Tabel 1

Audience reports dan behavior report

\begin{tabular}{|c|c|c|}
\hline No. & Item & Data \\
\hline 1 & $\begin{array}{l}\text { Sessions (jumlah } \\
\text { kunjungan) }\end{array}$ & 5.056 \\
\hline 2 & $\begin{array}{l}\text { Number of sessions user } \\
\text { (jumlah kunjungan per } \\
\text { pengguna) }\end{array}$ & 1.23 \\
\hline 3 & $\begin{array}{l}\text { Pages/session (jumlah } \\
\text { halaman diakses per } \\
\text { kunjungan) }\end{array}$ & 6.54 \\
\hline 4 & $\begin{array}{l}\text { Avg. session duration } \\
\text { (rerata durasi per } \\
\text { kunjungan) }\end{array}$ & 00.02 .50 \\
\hline 5 & $\begin{array}{l}\text { Returning visitors } \\
\text { (pengunjung berulang) }\end{array}$ & $453(9.9 \%)$ \\
\hline 6 & Devices (Sarana akses) & $\begin{array}{l}\text { Desktop } \\
(60,48 \%), \\
\text { mobile } \\
(38,26 \%), \\
\text { tablet }(1,26 \%)\end{array}$ \\
\hline 7 & $\begin{array}{l}\text { Avg. page load time in sec. } \\
\text { (rerata waktu loading) }\end{array}$ & 13.21 \\
\hline 8 & $\begin{array}{l}\text { Avg. server response time in } \\
\text { sec. (rerata waktu respon } \\
\text { dari server) }\end{array}$ & 0.22 \\
\hline
\end{tabular}

Sumber: Hasil penelitian, 2019

Hasil olah data dengan tingkat signifikansi $a=5 \%$; $r$ tabel untuk alfa 5\% dan $\mathrm{df}=65-2=63$ adalah 0.2423; nilai $\mathrm{r}>0$ dan $>0.2423$, maka dapat dikatakan valid. Hasil perhitungan dengan SPSS, 25 butir dinyatakan valid semuanya. Hasil olah data dengan tingkat signifikansi $a=5 \%$; diperoleh Cronbach's alpha $=0,990>0,60=$ a; reliabel. Hasil perhitungan dengan SPSS, ditentukan bahwa kuesioner harapan (25 item) dinyatakan valid dan reliabel semuanya.

Adapun hasil analisis rerata dan gap pada tabel 2 menunjukkan rerata nilai harapan variabel usability sebesar 4,24, dan rerata nilai kualitas aktual sebesar 3,61, dengan rerata kesenjangan sebesar -0,63. Untuk variabel service interaction quality, rerata nilai harapan sebesar 4,09 dan rerata nilai kualitas aktual sebesar 3,56 dengan rerata kesenjangan sebesar $-0,52$.

Tabel 2

Rerata kualitas dan kesenjangan

\begin{tabular}{|c|c|c|c|c|}
\hline No. & $\begin{array}{l}\text { Sub Variabel } \\
\text { Kode }\end{array}$ & Hrp & Akt & Gap \\
\hline 1. & U1 & 4,32 & 3,66 & $-0,66$ \\
\hline 2. & U2 & 4,25 & 3,68 & $-0,57$ \\
\hline 3. & U3 & 4,2 & 3,65 & $-0,55$ \\
\hline 4. & U4 & 4,29 & 3,77 & $-0,52$ \\
\hline 5. & U5 & 4,17 & 3,27 & $-0,9$ \\
\hline 6. & U6 & 4.15 & 3,52 & $-0,63$ \\
\hline 7. & U7 & 4,16 & 3,56 & $-0,6$ \\
\hline 8. & U8 & 4,26 & 3,76 & $-0,5$ \\
\hline \multicolumn{2}{|c|}{ Rerata } & 4,24 & 3,61 & $-0,63$ \\
\hline 9 & $\mathrm{I} 1$ & 4,22 & 3,71 & $-0,51$ \\
\hline 10 & $\mathrm{I} 2$ & 4,27 & 3,89 & $-0,38$ \\
\hline 11. & I3 & 4,18 & 3,57 & $-0,61$ \\
\hline 12. & $\mathrm{I} 4$ & 4,23 & 3,73 & $-0,5$ \\
\hline 13. & I5 & 4,2 & 3,59 & $-0,61$ \\
\hline 14. & I6 & 4,17 & 3,41 & $-0,76$ \\
\hline 15. & I7 & 4,14 & 3,55 & $-0,59$ \\
\hline \multicolumn{2}{|c|}{ Rerata } & 4,2 & 3,64 & $-0,57$ \\
\hline 16. & S1 & 4,19 & 3,7 & $-0,49$ \\
\hline 17. & S2 & 4,2 & 3,8 & $-0,4$ \\
\hline 18. & S3 & 4,16 & 3,74 & $-0,42$ \\
\hline 19. & S4 & 4,04 & 3,52 & $-0,52$ \\
\hline 20 & S5 & 4,02 & 3,41 & $-0,52$ \\
\hline 21. & S6 & 4 & 3,33 & $-0,67$ \\
\hline 22. & S7 & 4,02 & 3,42 & $-0,6$ \\
\hline \multicolumn{2}{|c|}{ Rerata } & 4,09 & 3,56 & $-0,52$ \\
\hline 23. & E1 & 4,2 & 3,32 & $-0,88$ \\
\hline 24. & E2 & 4,17 & 3,63 & $-0,54$ \\
\hline 25. & E3 & 4,16 & 3,43 & $-0,73$ \\
\hline \multicolumn{2}{|c|}{ Rerata } & 4,18 & 3,46 & $-0,72$ \\
\hline \multicolumn{2}{|c|}{ Rerata Semua Butir } & 4,18 & 3,58 & $-0,59$ \\
\hline
\end{tabular}

Untuk variabel service interaction quality, rerata nilai harapan sebesar 4,09 dan rerata nilai kualitas aktual sebesar 3,56 
dengan rerata kesenjangan sebesar $-0,52$. Kesenjangan terbesar didapat oleh sub variabel S6 website memudahkan berkomunikasi dengan organisasi, sebesar 0,67 . Variabel entertainment rerata nilai harapan sebesar 4,18 dan rerata nilai kualitas aktual sebesar 3,46 dengan rerata kesenjangan sebesar -0,72. Kesenjangan terbesar didapatkan sub variabel E1 website memiliki daya tarik visual dan desain yang estetis, sebesar $-0,88$. Rerata seluruh atribut kualitas aktual sebesar 3,58 dan rerata harapan sebesar 4,18 dengan kesenjangan total sebesar $-0,59$.

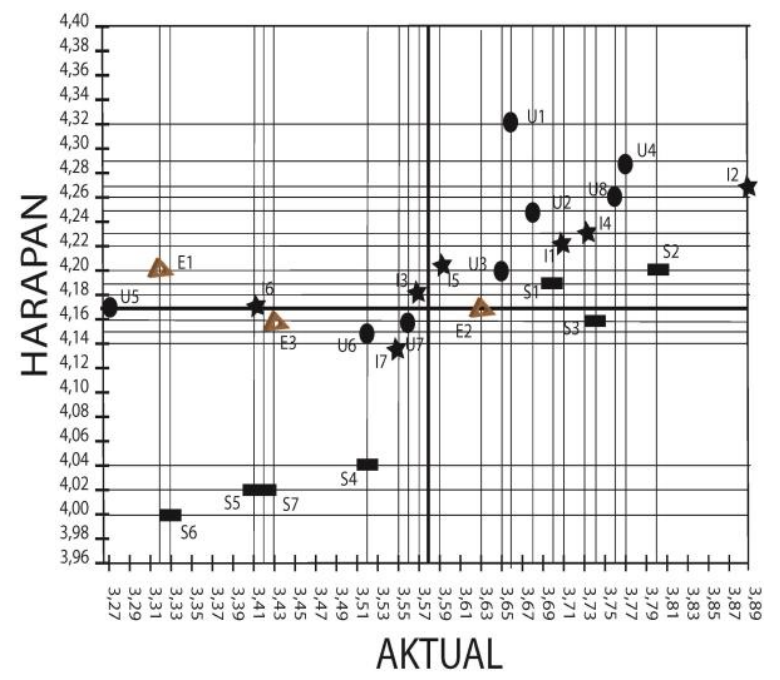

Gambar 3. Diagram analisis importance and performance analysis

Sumber: Hasil penelitian, 2019

Analisis kuadran pada gambar 3 menghasilkan data berikut. Kuadran I berisi 4 atribut prioritas perbaikan, sebagian besar atribut (12 atribut) berada di kuadran II. Kuadran III berisi 8 atribut, sedangkan kuadran IV hanya berisi 1 atribut. Diagram kuadran di atas menunjukkan sebaran atribut pada tiap kuadran disertai dengan keterangan tindakan yang diperlukan. Atribut terbanyak berada di kuadran II sebanyak 12 atribut. Kuadran II dengan karakteristik kualitas tinggi dan harapan juga tinggi. Banyaknya atribut di kuadran ini menjadi pertanda bahwa responden pada umumnya menganggap kualitas website sudah memadai. Tetapi terdapat 4 atribut di kuadran I yang menunjukkan kualitas rendah dan harapan tinggi, yang harus diperbaiki yaitu U5, I3, I6, dan E1. Sedangkan kuadran III kualitas rendah, harapan juga rendah, bisa diabaikan, berisi 8 atribut. Kuadran IV kualitas tinggi, tetapi harapan rendah, berisi 1 atrubut yang berlebihan dan bisa diabaikan.

Hasil reduksi data kuesioner terbuka digunakan untuk menggali secara rinci, atribut yang termasuk prioritas untuk diperbaiki, yaitu U5, I3, I6, dan E1. Atribut S6 tidak prioritas, tetapi berdasarkan analisis kualitatif merupakan atribut penting untuk diperbaiki. Keabsahan data dilakukan menggunakan triangulasi sumber, dan metode wawancara dengan staf pengembang website.

Berdasarkan data tabel 3, responden menghendaki perbaikan tampilan dengan perubahan aspek desain dan dekorasi, tetapi menurut pengembang website perbaikan desain membutuhkan staf dengan keahlian spesialis desainer grafis yang belum tersedia di perpustakaan. Ketepatan waktu menjadi salah satu aspek utama perbaikan. Berdasarkan data tabel 3, responden menghendaki perbaikan dengan penambahan anotasi, translator, indeks judul, indeks kata kunci, indeks pengarang, kategorisasi koleksi berdasarkan daerah dan tahun terbit atau subyek, serta recommended search. Semuanya layak ditambahkan, termasuk recommended search yang merupakan pengembangan fitur kecerdasan buatan. Temuan ini sejalan dengan hasil penelitian Feranisa, Sukaesih, and Erwina (2017) yang menekankan pentingnya anotasi sebagai informasi ringkas dan lengkap tentang isi bahan pustaka, dalam penyusunan bibliografi tentang debus Banten. 
Ketersediaan koleksi langka digital perlu ditingkatkan. Berdasarkan data tabel 3, responden menghendaki penambahan link koleksi langka dari Indonesia maupun dunia, terutama dari Universitas Leiden dan British library. Koleksi yang juga ingin ditambahkan yaitu lingkup Asia, China, Jepang, serta Indocina yang fisik bukunya juga banyak dimiliki oleh Perpustakaan UGM.

Efek visual perlu diterapkan pada perancangan website. Berdasarkan data tabel 3, responden menginginkan efek visual yang lebih menarik ketika membalik halaman, yaitu penggunaan aplikasi flippingbook viewer yang bersifat interaktif. Tetapi berdasarkan data triangulasi sumber dengan staf pengembang website, aplikasi tersebut belum sepenuhnya aman karena masih tetap dapat diunduh menggunakan akselerator. Penggunaan infografik sebagai media yang memiliki dampak visual lebih kuat, menarik, jelas dan mudah dipahami, ternyata juga sangat diharapkan pengguna. Temuan ini sejalan dengan hasil penelitian oleh Resnatika, Sukaesih, and Kurniasih (2018) yang berhasil membuktikan bahwa infografik mampu menarik lebih banyak perhatian (attention) penggunanya.

Meskipun berdasarkan analisis kuadran atribut S6 bukan prioritas perbaikan, tetapi berdasarkan data tabel 3 triangulasi sumber dengan staf pengembang website, atribut tersebut merupakan fitur sangat penting di masa depan. Data triangulasi berikut menunjukkan responden menghendaki penambahan fitur komentar atau ulasan pada tiap buku, dan juga livechat untuk saran dan pertanyaan.

Pemuatan (loading) konten yang terlalu lama, dan tampilan serta atribut website yang belum sesuai dengan piranti akses bisa menyebabkan keengganan pengunjung, sedikitnya kunjungan berulang, dan juga pendeknya durasi kunjungan. Akses melalui piranti mobile jelas akan terpengaruh, karena keterbatasan spesifikasi. Permasalahan loading terlalu lama bisa diatasi dengan meningkatkan kompresi file serta meningkatkan kapasitas traffic jaringan internet. Tjiptasari (2017) menyebutkan bahwa untuk keperluan pengarsipan digital, sebaiknya menggunakan format standar seperti Portable Document Format (PDF). Format tersebut cukup mudah dilakukan kompresi untuk mengurangi ukuran file, sehingga meringankan beban waktu pemuatan.

Analisis gap menunjukkan kesenjangan pada semua atribut, ditandai dengan nilai $\mathrm{Q}<0$ negatif, dan rerata total $-0,59$, yang dapat diartikan bahwa kualitas aktual website koleksi langka belum mampu memenuhi harapan pengguna. Hasil tersebut menegaskan perlunya perbaikan menyeluruh di semua variabel dan atributatributnya. Kesenjangan terbesar terjadi pada variabel entertainment sebesar -0,72, variabel tersebut paling mengecewakan. Atribut dengan kesenjangan terbesar yaitu U5 sebesar -0,9; disusul E1 sebesar -0,88; I6 sebesar -0,76; serta $\mathrm{S6}$ sebesar -0,67.

Analisis kuadran berhasil memetakan prioritas perbaikan. Kuadran I harapan tinggi, tetapi kualitas aktual sangat rendah, terjadi kesenjangan sangat besar. Kuadran ini berisi 4 atribut (U5, E1, I6 dan I3) yang menjadi prioritas yang harus diperbaiki. U5 atribut tampilan website, menjadi masalah utama yang harus diperbaiki karena dianggap kurang menarik. Atribut E1 daya tarik visual dan disain estetis juga dinilai kurang menarik. Sedangkan atribut I6 website dianggap belum menyediakan informasi secara memadai, belum cukup rinci. Demikian 
juga atribut I3, website dianggap belum tepat waktu dalam menyediakan informasi, masih terlalu lambat. Atribut lainnya dalam kategori sebaiknya dipertahankan, diabaikan, dan bisa dikurangi.

Analisis kualitatif menghasilkan masukan berharga berupa informasi rinci perbaikan yang dikehendaki pengguna. Masalah utama adalah tampilan U5, diharapkan desain website dirancang dengan dekorasi bernuansa sejarah atau daerah yang lebih sesuai dengan kondisi buku langka yang banyak mengkaji sejarah, kebudayaan dan adat istiadat. Perubahan ini membutuhkan keahlian spesialis desainer grafis yang mengerti tentang seni dan estetika, tetapi staf dengan spesifikasi tersebut belum tersedia di perpustakaan. Temuan tersebut sesuai dengan penjelasan Boro (2018), bahwa website masa depan semakin interaktif, memadukan berbagai format digital dan audio visual, serta berbagai keahlian TI. Demikian juga aspek daya tarik visual dan estetis E1, diharapkan menggunakan teknologi flipping book yang lebih menarik dan interaktif, meningkatkan minat pengunjung berinteraksi dengan website, tetapi piranti lunak tersebut juga rentan terhadap upaya download menggunakan akselerator. Belum ada viewer yang aman.

Berdasarkan hasil analisis di atas, susunan pengembangan website dengan memperbaiki beberapa atribut kualitas website prioritas sebagai berikut. Pertama, waktu loading. Perbaikan dapat dilakukan melalui peningkatan kompresi file dan penambahan bandwidth, yang diharapkan dapat meningkatkan kunjungan dan durasi. Kedua, piranti akses mobile. Rancangan website dapat disesuaikan dengan tren peningkatan akses mobile. Ketiga, tampilan. Perbaikan tampilan melalui perubahan desain dan dekorasi bernuansa sejarah atau daerah. Perubahan ini membutuhkan spesialis desainer grafis yang belum ada di perpustakaan.

Keempat, daya tarik visual. Perbaikan secara visual dan interaktif dapat dilakukan menggunakan flipping book viewer. Namun aplikasi tersebut belum sepenuhnya aman karena file masih dapat diunduh dalam bentuk teks lengkap (fulltext) menggunakan akselerator. Infografik merupakan visualisasi informasi yang dapat diupayakan pustakawan. Kelima, konten informasi rinci. Peningkatan ketersediaan konten dilakukan melalui penambahan link koleksi langka digital Indonesia dan dunia khususnya dari Universitas Leiden dan British library.

Keenam, informasi tepat waktu. Ketepatan waktu ditingkatkan melalui penambahan translator multi bahasa dalam tab baru (plugin), indeks, kategorisasi koleksi, dan kecerdasan buatan (recommended search). Perbaikan ini diharapkan dapat meningkatkan efisiensi dan efektivitas temu kembali informasi. Pustakawan dapat berperan dalam penyediaan anotasi yang memudahkan untuk mengetahui isi buku. Ketujuh, kemudahan berkomunikasi, untuk meningkatkan interaksi antar pemustaka dan pustakawan, ditambahkan kolom review tiap judul buku, serta live chat.

\section{SIMPULAN}

Penelitian menghasilkan beberapa temuan penting yang menjadi dasar rencana pengembangan website koleksi langka menuju era industri 4.0. Kinerja website belum menggembirakan, baik dari segi jumlah kunjungan, kunjungan berulang, maupun durasi kunjungan. Waktu loading masih terlalu lama yang bisa menyebabkan keengganan pengunjung. 
Akses melalui piranti mobile juga belum sesuai standar menurut statistik dunia. Temuan lainnya yaitu bahwa pengguna menghendaki perbaikan setidaknya pada 5 atribut kualitas website, meskipun analisis kesenjangan menunjukkan adanya kesenjangan di semua atribut kualitas. Kelima atribut tersebut yaitu tampilan (U5), daya tarik visual (E1), konten informasi (I6), informasi tepat waktu (I3), serta kemudahan berkomunikasi (S6). Berdasarkan temuan-temuan tersebut, dirumuskan rencana pengembangan website dengan beberapa upaya. Pertama, perbaikan waktu loading menggunakan kompresi file dan perbaikan bandwidth. Kedua, rancangan website menyesuaikan tren penggunaan piranti mobile. Ketiga, perancangan desain baru bernuansa sejarah dan daerah. Keempat, penggunaan flipping book viewer yang lebih interaktif, tetapi belum sepenuhnya aman, serta penambahan infografik. Kelima, penambahan link koleksi langka digital Indonesia dan dunia terutama dari Universitas Leiden dan British library, serta koleksi lingkup Asia. Keenam, penambahan translator, indeks, anotasi, serta recommended search. Ketujuh, penambahan kolom komentar dan ulasan, serta live chat. Untuk mengakomodir kebutuhan pengembangan website yang sesuai kemajuan sains dan teknologi era industri 4.0, perlu dilakukan penambahan staf spesialis desain grafis yang memiliki keahlian desain website. Demikian juga dengan staf yang memiliki keahlian dalam pemrograman menggunakan fitur kecerdasan buatan karena tuntutan pengguna agar website semakin cerdas dan interaktif. Hal ini dilakukan untuk mendukung kinerja temu kembali informasi. Disamping upaya tersebut, peningkatan ketersediaan konten digital melalui penambahan link khususnya dari Universitas Leiden dan British Library merupakan langkah strategis. Penelitian lanjutan sangat penting dilakukan. Metodenya bisa menggunakan evaluasi atau eksperimen pengujian kinerja setelah dilakukan perbaikan dan pengembangan website. Penelitian tersebut akan menghasilkan pengetahuan seberapa signifikan peningkatan kinerja yang didapatkan, serta dapat diketahui berbagai batasan dan kendala yang dihadapi dalam upaya pengembangan website.

\section{DAFTAR PUSTAKA}

Ali, I. (2012). National Library Of Indonesia branding strategies through ancient manuscript and rare books collection. International Conference On Libraries: "Transformation To Humanize Libraries" 2nd - 4th July 2012, Renaissance Hotel Kota Bharu, Kelantan., 1-6. http:/ /eprints.usm.my/33031/1/Nati onal_library_of_republic_Indonesia_ MUHA.pdf

Amarin, N. Z. (2015). Web 3.0 and its reflections on the future of e-learning. Academic Journal of Science, 04(02), 115-122.

https:/ / www.researchgate.net/profile /Nidal_Amarin/publication/32152735 9_Nidal_Amarin/links/5a2659b8aca27 27dd8811c51/Nidal-Amarin.pdf

Andayani, U. (2013). Analisis pemanfaatan katalog online berbasis web (WebPac) dengan menggunakan google analytics. Jurnal Al-Maktabah, 12(1), 1322.

http:/ /journal.uinjkt.ac.id/index.php /almaktabah/article/view/1593/1336

Astuti, A. P., \& Sari, P. K. (2016). Analisis kualitas website Lazada Indonesia berdasarkan metode webqual 4.0 dan 
pengaruhnya terhadap kepuasan pengguna. E-Proceeding of Management. https:/ /libraryeproceeding.telkomuni versity.ac.id/index.php/management /article/viewFile/1472/1403

Baiti, A. A., Suprapto, \& Rachmadi, A. (2017). Pengukuran kualitas layanan website Dinas Pendidikan Kota Malang dengan menggunakan metode webqual 4.0 dan IPA. Jurnal Pengembangan Teknologi Informasi Dan Ilmu Komputer, 1(9), 885-892. http://jptiik.ub.ac.id/index.php/j-

ptiik/article/view/273

Baltes, L. P. (2015). Content marketing - the fundamental tool of digital marketing. Bulletin of the Transilvania University of Braşov Series V: Economic Sciences, 8(2), 111-118.

https://pdfs.semanticscholar.org/73e 0/21ce79791040af99ab2353e062f08caac c53.pdf?_ga=2.255503176.1743103281.1 590513412-2051016010.1590513412

Bekavac, I., \& Pranicevic, D. G. (2015). Web analytics tools and web metrics tools: An overview and comparative analysis. Croatian Operational Research Society CRORS, 6(2), 373-386. https://hrcak.srce.hr/ojs/index.php/ crorr/article/view/2810

Boro, K. (2018). The latest digital preservation technology \& system. Sosialisasi Teknologi Preservasi, Hotel TARA,Yogyakarta, 5-6 September 2018, 1-7.

Clement, J. (2019). Mobile internet - statistics $\mathcal{E}$ facts. Mobile Internet and Apps. https://www.statista.com/topics/779 /mobile-internet/

Feranisa, F., Sukaesih, \& Erwina, W. (2017). Rancang bangun bibliografi beranotasi debus Banten. Jurnal Kajian Informasi $\mathcal{E}$ Perpustakaan, 5(1), $65 \quad$ - 78. https://doi.org/10.24198/jkip.v5i1.11
194

Ferreira, H. P., \& Fernandes, P. O. (2015). Importance-performance analysis applied to a laboratory supplies and equipment company. Procedia Computer Science, 64(1), 824-831. https://doi.org/10.1016/j.procs.2015.0 8.634

He, Y., Ma, Y. H., \& Zhang, X. R. (2017). Digital heritage theory and innovative practice. The International Archives of the Photogrammetry, Remote Sensing and Spatial Information Sciences, Volume XLII-2/W5, 2017 26th International CIPA Symposium 2017, 28 August-01 September 2017, Ottawa, Canada., 335342. https://doi.org/10.5194/isprsarchives-XLII-2-W5-335-2017

Hendriadi, A. A., \& Dedih. (2014). Analisis web menggunakan google analytic untuk menyajikan laporan data situs dalam proses optimasi. Jurnal Ilmiah Solusi, 1(4), 7-19. https:/ /journal.unsika.ac.id/index.ph $\mathrm{p} /$ solusi/article/view/64

Kadar, J. A., Napitupulu, D., \& Jati, R. K. (2017). Analysis of factors influencing the quality of intranet website based on webQual approach case study in agency X. 2017 3rd International Conference on Science in Information Technology (ICSITech), 572-577. https:/ / doi.org/10.1109/ICSITech.201 7.8257169

Khanzode, K. C. A., \& Sarode, R. D. (2016). Evolution of the world wide web: From web 1.0 to 6.0. International Journal of Digital Library Services, 6(2), 1-11.

http:/ /www.ijodls.in/uploads/3/6/0 /3/3603729/ijodls121.pdf

Margana, S. (2013). Pemanfaatan koleksi langka dalam kegiatan akademis. Bimtek Pengelolaan Perpustakaan Koleksi 


\section{Langka.}

http:// prisekip.blog.ugm.ac.id/ files/2 015/12/LAPORAN-BIMTEK-

PERPUSTAKAAN-2.pdf

Masrek, M. N., \& Gaskin, J. E. (2016). Assessing users satisfaction with web digital library: The case of Universiti Teknologi MARA. The International Journal of Information and Learning Technology, 33(1), 36-56. https:/ / doi.org/10.1108/IJILT-062015-0019

Napitupulu, D. (2017). Analysis of factors affecting the website quality based on webqual approach: Study case: XYZ University. International Journal on Advanced Science Engineering Information Technology, 7(3), 792-798. https://doi.org/10.18517/ijaseit.7.3.17 48

Nielsen, J. (2016). Using web archives in research - an introduction. Netlab. http:/ / www.netlab.dk/wpcontent/uploads/2016/10/Nielsen_U sing_Web_Archives_in_Research.pdf

Nurhadi, A., Yunita, N., Mukhayaroh, A., \& Sahirudin, A. (2019). Implementation of webqual 4.0 for measuring the quality of Baznas.Go.Id website for user satisfaction. Journal Publications \& Informatics Engineering Research, 3(2), 260-264. https:// doi.org/10.33395/sinkron.v3i 2.10103

Pramono, S., Sarma, M., \& Munandar, J. M. (2017). Kepuasan dan loyalitas siswa dan orang tua terhadap penggunaan layanan online berdasarkan kualitas pelayanan dan kualitas tampilan laman (web) di SMK Negeri 1 kota Bogor. Jurnal Manajemen Dan Organisasi, 8(1), 43-59. https://doi.org/10.29244/jmo.v8i1.18 600
Rahayu, D., Utami, E., \& Luthfi, E. T. (2018). Analysis of quality from users perspective for develop website. International Conference on Electrical, Electronic, Informatics and Vocational Education (ICE-ELINVO 2018), 1-9. https:/ / doi.org/10.1088/17426596/1140/1/012051

Redkina, N. S. (2018). Library sites as seen through the lens of web analytics. Automatic Documentation and Mathematical Linguistics, 52(2), 91-96. https:/ / doi.org/10.3103/S0005105518 020073

Resnatika, A., Sukaesih, \& Kurniasih, N. (2018). Peran infografis sebagai media promosi dalam pemanfaatan perpustakaan. Jurnal Kajian Informasi $\mathcal{E}$ Perpustakaan, 6(2), 183-196. https:/ / doi.org/10.24198/jkip.v6i2.15 440

Rezende, N. E. H., Moura, L. R. C., Vasconcelos, F. C. W., \& Cunha, N. R. da S. (2017). Proposition and test of a quality assessment extension webQual model in Brazil. Review of European Studies, 9(2), 74-90. https://doi.org/10.5539/res.v9n2p74

Richardson, J., Milovidov, E., \& Schmalzried, M. (2017). Internet literacy handbook: Supporting users in the online worlds. Council of Europe. https:/ / rm.coe.int/internet-literacyhandbook/1680766c85

Rono, L. D. C. (2018). Microcredit and its relationship to the growth of small and medium enterprises in Konoin Subcounty, Kenya. International Journal of Advanced Research (IJAR), 6(4), 961968. https://doi.org/10.21474/IJAR01 $/ 6935$

Shia, B. C., Chen, M., Ramdansyah, A. D., \& Wang, S. (2016). Measuring customer satisfaction toward localization 
website by webQual and importance performance analysis: Case study on AliexPress Site in Indonesia. American Journal of Industrial and Business Management, 6(2), 117-128. https://doi.org/10.4236/ajibm.2016.6 2012

Shimray, S. R., \& Ramaiah, C. K. (2017). Issues in preservation of digital cultural heritage. 11th International CALIBER-2017 Anna University,Chennai, Tamil Nadu 02-04 August, 2017, 146-157. https:/ / pdfs.semanticscholar.org/6af9 /96c563f40808f0db283115994fdbcfd1b1 c9.pdf

Subagyo, H. (2018). Perpustakaan dan tantangan era industri 4.0. Seminar Nasional Forum Perpustakaan Khusus Indonesia, Ruang Theater Perpustakaan Nasional RI Jakarta, 5 November 2018, 115.

Subrahmanyam, A. (2017). Relationship between service quality, satisfaction, motivation and loyalty: A multidimensional perspective. Quality
Assurance in Education, 25(2), 171-188. https:/ / doi.org/10.1108/QAE-042013-0016

Sugiyono. (2011). Metode penelitian kuantitatif, kualitatif dan kombinasi (mixed methods). Alfabeta.

Tjiptasari, F. (2017). Perceived usefullness (persepsi kegunaan) pengelolaan arsip digital menggunakan sistem informasi kearsipan dinamis (SIKD). Jurnal Kajian Informasi \& Perpustakaan, 5(2), 111-126.

https:/ / doi.org/10.24198/jkip.v5i2.12 64

Tripathi, S. (2018). Digital preservation: Some underlying issues for long-term preservation. Library $\mathrm{Hi}$ Tech News, 35(2), 8-12. https:/ / doi.org/10.1108/LHTN-092017-0067

Walidin, W., Saifullah, \& Tabrani, Z. A. (2015). Metodologi penelitian kualitatif $\mathcal{E}$ grounded theory. FTK Ar-Raniry Press. https:/ / www.academia.edu/34368497 /Metodologi_Penelitian_Kualitatif _Grounded_Theory \%0A 


\section{DAFTAR TABEL}

Tabel 3

Reduksi data kualitatif

\begin{tabular}{lll}
\hline Sub variabel & Pertanyaan & Jawaban \\
\hline U5 Tampilan & Bagaimanakah sebaiknya tampilan & "Tampilan sebaiknya diperbaiki dengan desain dan \\
website sangat & website koleksi langka agar menarik? & dekorasi bernuansa sejarah dan daerah sesuai jenis \\
menarik & & koleksinya."
\end{tabular}

Triangulasi sumber staf pengembang website:

\section{I3 Website} menyediakan informasi tepat waktu

I6 Website menyediakan informasi rinci

E1 Website memiliki daya tarik visual dan desain yang estetis
Sebagian besar koleksi langka digital berbahasa Belanda. Fitur apakah yang diperlukan untuk mempermudah pencarian informasi?

Triangulasi sumber staf pengembang website:

Sebagian besar koleksi langka digital berupa buku yang mengkaji Indonesiana. Konten digital apakah yang perlu ditambahkan?

Triangulasi sumber staf pengembang website:

Bagaimanakah sebaiknya agar website koleksi langka lebih menarik?

Triangulasi sumber staf pengembang website:

\section{S6 Website}

memudahkan

berkomunikasi

dengan

organisasi
Bagaimanakah sebaiknya website koleksi langka agar lebih interaktif?

Triangulasi sumber staf pengembang website:
"Permasalahan desain membutuhkan spesialis desainer grafis, yang memahami nilai seni suatu tampilan. Tetapi staf dengan spesifikasi tersebut belum ada di perpustakaan."

"Diperlukan translator bahasa Indonesia - Belanda Inggris; indeks kata kunci, judul dan pengarang; Kategorisasi koleksi berdasarkan tahun terbit, subyek dan daerah; recommended search; serta anotasi isi buku langka."

"Anotasi sangat penting, karena tujuan utama pengunjung adalah kontennya sehingga sangat penting membenahi fasilitas yang memudahkan pengunjung mengakses konten. Semua fasilitas translator, indeks, anotasi, kategorisasi koleksi maupun fitur recommended search sangat layak direalisasikan."

"Perlu ditambahkan link buku langka digital Indonesia dan dunia, versi digital manuskrip Indonesia koleksi Universitas Leiden dan British Library, selain itu juga koleksi lingkup Asia, China, Jepang, dan Indocina."

"Sangat layak ditambahkan dan bisa juga diupayakan oleh pustakawan."

"Penting dimodifikasi agar menampilkan visualisasi ketika membalik halaman. Serta infografik."

"Belum ada aplikasi viewer yang betul-betul aman. Aplikasi $P d f$ viewer memungkinkan file $p d f$ diunduh dengan accelerator. Sedangkan pada flipping book, file image dirubah ke bentuk video, yang masih tetap dapat diunduh dengan accelerator. Infografik merupakan konten yang bisa diupayakan oleh pustakawan."

"Diperlukan kolom komentar, review, ulasan tiap judul buku; livechat untuk saran dan feedback, serta ask librarian via sosmed."

"Kolom komentar dan ulasan merupakan fitur penting saat ini dan di masa depan, demikian juga livechat." 